\title{
Recording of offences on police domestic violence call outs
}

\author{
Fagerlund, Monica
}

2018

Fagerlund, M , Kääriäinen , J \& Ellonen , N 2018 , ' Recording of offences on police domestic violence call outs ' , International Journal of Comparative and Applied Criminal Justice , vol. 42 , no. 2-3 , pp. 119-137 . https://doi.org/10.1080/01924036.2017.1364277

http://hdl.handle.net/10138/298708

https://doi.org/10.1080/01924036.2017.1364277

Downloaded from Helda, University of Helsinki institutional repository.

This is an electronic reprint of the original article.

This reprint may differ from the original in pagination and typographic detail.

Please cite the original version. 


\section{Recording of Offences on Police Domestic Violence Call Outs}

Monica Fagerlund (corresponding author)

Police University College, Tampere, Finland

P.O. Box 123, 33721 Police University College, Tampere, Finland. monica.fagerlund@ poliisi.fi, $+358295483825$

Monica A. Fagerlund, MSSoc, works as a researcher in the Police University College of Finland and is a $\mathrm{PhD}$ Candidate in the University of Tampere, School of Social Sciences and Humanities. Fagerlund was actively involved in conducting the latest Finnish Child Victim Survey in 2013 and is currently working in research projects concerning police response to domestic violence and the Police Barometer, with funding from the Finnish Ministry of the Interior.

Juha Kääriäinen

Institute of Criminology and Legal Policy, University of Helsinki, Helsinki, Finland

P.O. Box 24, FI-00014 University of Helsinki, Finland. juha.kaariainen@helsinki.fi. $+358294120849$

Juha T. Kääriäinen, $\mathrm{PhD}$, is a postdoctoral researcher at the University of Helsinki, Institute of Criminology and Legal Policy. Kääriäinen has several international and national publications on police-community relations, violence and social capital.

\section{Noora Ellonen}

School of Social Sciences and Humanities, University of Tampere, Tampere, Finland

33014 University of Tampere, Finland. noora.ellonen@uta.fi. +358503187647

Noora E. Ellonen, PhD, works as a University Lecturer at the University of Tampere, School of Social Sciences and Humanities. Ellonen has studied the prevalence of violence against children in the Nordic countries, including being actively involved in the conducting of the first Finnish Child Victim Survey in 2008. She has also studied on the work of the police and the process of criminal process related to violence against children.

Word count: 11,811

Acknowledgements: This is an Author's Accepted Manuscript of an article published by Taylor \& Francis in International Journal of Comparative and Applied Criminal Justice on 10 Aug 2017, available online at: http://www.tandfonline.com/ [http://dx.doi.org/10.1080/01924036.2017.1364277]. 


\title{
Recording of Offences on Police Domestic Violence Call Outs
}

\begin{abstract}
Due to new legislation passed in 2011, Finnish police have been legally obligated to record and investigate all assaults, including petty assaults, occurring in close relationships. Referred to as domestic violence (DV), these assaults can be prosecuted even without victim consent. Much like pro- and mandatory arrest policies, this reform was aimed at decreasing victim and police discretion, based on the assumption that recording and preliminary investigation of every domestic violence incident would help prevent further violence. Comparison between police call outs and the number of offences indicate that in reality not every DV incident is recorded. Using Police and Emergency Call Database data merged with 410 police officer survey responses, the current study presents the first empirical results on legal and extra-legal factors associated with recording DV as an offence in Finland. Factors explaining non-recording are discussed based on police officers' freetext comments, and implications for policy and practice are presented.
\end{abstract}

Keywords: domestic violence, policing, intimate partner violence, police discretion, criminal justice policy

\section{Introduction}

When domestic violence (hereafter DV) was raised as a central issue by feminists in the 1970s the failure of police officers to sensitively respond to victims of these crimes, predominantly women, also started getting attention (Sherman \& Berk, 1984; Jordan, 2002; Leisenring, 2012). Police are the front line responders to DV (Trujillo \& Ross, 2008; Horwitz et al., 2011), yet before the 1980's there was a well-established reluctance to consider DV disturbances as real police work, and these attitudes were recognized at least in the United States, Britain, Australia and New Zealand (Newbold \& Cross, 2008). Since then, increasingly aggressive responses by criminal justice systems have been introduced to tackle DV and intimate partner violence (Bourg \& Stock, 1994; Leisenring, 2012). For this purpose, pro- and mandatory arrest policies have been adopted in a majority of the United States. This additionally has had a revolutionary effect on the adoption of similar arrest policies internationally (Felson, Ackerman \& Gallagher, 2005; Frye, Haviland \& Rajah, 2007; Newbold \& Cross, 2008). Later results concerning the deterrent effect of arrest on DV have been inconsistent (Felson et al., 2005) and these policies have also received criticism (e.g. Barrett, Pierre \& Vaillancourt, 2011). 
DV arrest policies have been widely studied, whereas literature on other police responses and their effects, as well as results from other than Anglo-Saxon countries, are more difficult to obtain. In the UK a positive action policy has been deployed instead of arrest policies (Robinson et al. 2016). In the Finnish context, in which this study was conducted, a pro- or mandatory arrest policy concerning DV call outs does not exist. However, during the past two decades the Finnish Criminal Code (Ministry of Justice, 2012) has undergone reforms that have aimed at a stronger legal response to DV. Compared to other Northern countries and some Western European countries, and in relation to number of citizens, a proportionately high number of women are killed in Finland annually as a result of DV (Piispa et al., 2006), although recent reports show a steady decline in these numbers (Lehti, 2016).

In Finland the Council of Europe Istanbul Convention for preventing and combating violence against women and DV was ratified in April 2015, and it entered into force on August 2015. The Convention binds signatories to several profound actions on the level of attitudes, services, operational principles, and legislation, also highlighting governmental support for law enforcement agencies (Council of Europe, 2011). The latest legal reform that affected policing DV took place in 2011 and changed Chapter 21 of the Finnish Criminal Code, Section 16: Right to bring charges. Before the 2011 reform the public prosecutor could only bring charges for petty assaults if the victim wanted to do so. Thus, the police would not conduct a pre-trial investigation if the victim would not press charges. As a result of the reform, even petty assaults are no longer considered complainant offences in cases where the victim and the perpetrator are in a close personal relationship. This legal reform has been compared to pro-arrest and mandatory arrest policies by researchers in Finland (Aaltonen, Salmi \& Kivivuori, 2014) but it could also be understood as application of a mandatory prosecution policy (Horwitz et al., 2011) or more specifically, mandatory recording of DV offences.

In 2015, the Finnish Police responded to 26,223 DV call outs and recorded 4,791 DV offences nationally (PolStat), so even considering false alarms, the number of DV-related offences is relatively modest compared to the number of DV call outs. Most of the assaults labelled as DV in Finland come to the attention of the police via DV call outs and approximately 28 percent of DVrelated offences have resulted from other sources, such as police investigation of some other crime (personal communiqué from PolStat, 2015). Thus, police actions on DV call outs are crucial for the implementation of the mandatory recording policy adopted in Finland. 
In this paper we examine the recording of offences on police DV call outs. Prior research on policing DV has, due to pro-arrest policies, focused on factors associated with arrest. It has been shown that, even though these policies in principle leave very little room for discretion in the decision-making of the victim and the police, some discretion still occurs and factors linked to arrest decisions vary (e.g. Horwitz et al. 2011; Bourg \& Stock, 1994). Even Sherman and Berk (1984, p. 270), the introducers of the concept of pro-arrest policy, have stated that it is best to leave "a loophole" for the police in assessing whether this policy is appropriate for each given case. In the Finnish context the equivalent interest is targeted at the factors associated with recording an offence, because the police are obligated by law to record all DV offences, and without reporting an offence the process of pre-trial investigation and consideration of charges will not begin. It is therefore crucial for the legal protection of the citizens and the police to examine which factors are associated with discretionary choices to record or not to record an offence.

The definition of a DV call out in Finland is restricted to physical violence, and because illegal threats are defined as complainant offences in the Finnish Criminal Code, this analysis is focused on physical violence perpetrated in close relationships. Close relationship is defined in the Finnish Criminal Code as "the offender's spouse or former spouse, sibling or direct ascending or descending relative or a person who lives or has lived in a joint household with the offender or otherwise is or has been in a corresponding personal relationship with the offender or is close to him or her" (Ministry of Justice, 2012). In so far as the Emergency Response Centre has received accurate information from the caller to label the call, sexual violence and homicide, for example, have a call out label separate from DV, and are thus excluded from this analysis. In this paper data from the Police and Emergency Centre (ERC) database is analysed together with survey responses by frontline police officers in one major police department, in order to attain the first academic results on policing DV and police discretion in Finland.

\section{Previous research}

There is a considerable variation in the terminology related to domestic violence (DV) in the literature. In some studies intimate partner violence (IPV) is used to highlight the relationship between two adults and patriarchal construction in heterosexual relationships as the context of violence (Douglas \& Hines, 2011), whereas using terms such as DV or family violence in the Finnish context are in some cases seen as dispelling this and presenting violence as a problem "of the family" (e.g. Holma \& Partanen, 2008) rather than paying attention to the person who is actually 
guilty of using violence. As can be concluded, for example, based on the selection of papers in reviews on this matter (see Hamberger \& Larsen, 2015), different phrasings such as DV, IPV, partner abuse, domestic abuse are often used as synonyms for the same phenomenon. In this paper DV is used because it translates from the context of the study: police DV call outs. DV call out or DV disturbance call are generally used in police terminology to describe police tasks related to violence on private premises and/or between family members and concerning other close relationships (e.g. Newbold \& Cross, 2008).

As, for example, Robinson and Chandek (2000) have noted, a considerable body of research has been dedicated to analysing factors that affect police arrest decisions on DV call outs, some include police charging the assailants (e.g. Brown 2004; Stewart \& Maddren, 1997), yet only a handful of studies also address other police responses (e.g. Sherman \& Berk, 1984; Barrett et al. 2011; Robinson, 2006; Hoyle \& Sanders, 2000). Arrest is obviously a different type of response than reporting an offence, in conjunction with the fact that legislation concerning both actions differ across countries and state governments. Even though the early support for arrest on DV call outs was promoted as a deterrent for future violent acts (Sherman \& Berk, 1984), it is, nonetheless, a short-term response separating the victim and the assailant compared to written recording of an offence, the latter aiming at a criminal investigation and possibly to conviction of the assailant. A few examples in the literature include analysing the police decision to charge the assailant, although, unlike the Finnish context, these studies are conducted in jurisdictions without a mandatory prosecution policy (Brown 2004; Stewart \& Maddren, 1997).

It can be expected that to some extent the same factors affecting arrest and charge decisions are relevant to police officers' decisions to record DV as an offence, as far as all of these responses are the first action police officers may take in each DV incident, and all of these responses have been subjected to reduced police discretion in their implementation. Therefore, we will next review the literature on factors affecting police arrest, and for relevant parts also concerning decisions to press charges. These factors will be used in our analysis to test whether similar factors also explain recording of offences on DV call outs.

Factors associated with police decisions to make arrests can be roughly divided into two groups: legal and extra-legal factors (Lee, Zhang \& Hoover, 2013; Stewart \& Maddren, 1997), and police actions have to be, first and foremost, based on legal norms. When the police are acting according to law and other official directives its operations are legitimate and open for public debate. Recording an offence in Finland is guided by the Criminal Investigation Act. According to the Act, 
the police are obligated to record the report without a delay "when an offence or an event that the reporting party suspects is an offence is reported to the criminal investigation authority" (Ministry of Justice, 2015, Chapter 3, Section 1). In addition, "The criminal investigation authority shall conduct an investigation when, on the basis of a report made to it or otherwise, there is reason to suspect that an offence has been committed" (Ministry of Justice, 2015, Chapter 3, Section 3).

The challenge is that the forms of violence vary greatly and the essential elements of an assault in the Criminal Code are defined broadly (Ministry of Justice, 2012) ${ }^{\mathrm{i}}$. Nonetheless, previous research has concluded that the characteristics of the violent act are the most important legal factor affecting police arrest decisions. Of these characteristics, injuries resulting from the violence and the possible use of weapons have explicitly been found to be connected to the decision to make an arrest (Lee et al. 2013; Phillips, 2008). Our legal factors in this study are therefore seriousness of violence and the likelihood of violence perceived by the police officers on a DV call out.

The actions of police officers cannot be fully guided and directed by laws and administrative regulations. In practical police work, such as responding to DV call outs, some level of discretion continues to exist in interpreting the official guidelines (e.g. Grant \& Rowe, 2011; Stewart \& Maddren, 1997). Studies have shown that, for example, gender of the victim, position of the informant and other extra-legal factors partly explain police decision-making on DV call outs.

Both women and men experience DV. According to the Finnish National Crime Victim Survey (NCVS) (Danielsson \& Salmi, 2013) five percent of women and two percent of men reported experiencing physical violence in an intimate partnership during the past 12 months. According to the results from the latest sweep of the NCVS, the difference between women and men in prevalence of experiencing DV is not statistically significant (Danielsson \& Kuitunen, forthcoming). DV against women is much more likely to come to the attention of the police compared to that against men: ten percent of incidents experienced by women and three percent of incidents experienced by men were reported to the police. The higher level of underreporting by male victims of DV can be partly explained by the seriousness of violence, as DV experienced by men tends to be less serious compared to experiences of women (Danielsson \& Salmi, 2013). On the other hand, it has been proposed that men are more ashamed of their victimization, resulting in them more often refraining from reporting violence by an intimate partner compared to women (Arnocky \& Vaillancourt, 2014; Felson \& Paré, 2005). Gendered attitudes towards violence may also affect the functioning of the criminal justice system so that DV against men is considered less serious than that against women. For example, a study by Lee and others (2013) found that DV 
incidents involving a female suspect and a male complainant were less likely to result in an arrest. In addition, in a study conducted in Canada (Brown, 2004) it was found that the entire process from recording an offence to convictions of the court treats DV by men considerably more severely than DV by women. In Brown's analysis gender appears to be the strongest independent factor explaining the severity of the response to DV by the criminal justice system (Brown, 2004, p. 107). Based on these examples, we have reason to assume that the victim's gender affects the probability of recording an offence so that violence against women is more likely to be recorded than violence against men.

DV call outs are brought to the attention of police because of a phone call to the Emergency Call Centre. The person calling is typically the victim or another person in the apartment or a neighbour who has witnessed the incident or has heard alarming noises. On some occasions the caller may be the assailant. It is possible that if the caller is a neighbour or an outside person, the victim may feel negatively about the police visiting the scene and may be reluctant to cooperate even if he or she has been battered. If the victim strictly denies the violence and no physical signs of it can be detected, there are very limited possibilities for the police to record an offence. Instead, when it is the victim who calls for help, it may be an expression that the victim wants criminal sanctions for the assailant. This is not always the case, and the immediate help to stop the violence may be victim's motive rather than punishing the assailant (Barrett et al. 2011; Johnson, 2007). One of the most important reasons for not reporting DV is the fear of how it will affect the future of a relationship and possible child welfare interventions when the situation comes to the attention of the authorities (e.g. Felson et al., 2002; Kaukinen, 2004). Regardless, we can expect that if the informant calling the emergency centre is the victim, the probability of the offence being recorded increases. Taking into account the possibility of a victim calling the police for reasons other than wanting an offence to be recorded and the assailant to be punished, we also expect that inquiring about the victim's consent decreases the probability of an offence being recorded.

In addition, studies have shown other significant factors related to police decisions to arrest. Literature concerning these factors is rather scarce, but some of them are worth taking into account when explaining police decision making to record DV call outs. We call these factors situational factors.

There are several studies indicating that in DV situations both parties often commit violent acts (see Hamberger \& Larssen, 2015 for review). For example, research conducted in the US has shown that arresting women has considerably increased due to obligations for the police to arrest persons 
suspected of DV. When the police have visited a scene, a common finding is that both parties have been violent and it is difficult to distinguish who initiated the violence (Leisenring, 2012).

Mutuality of violence can result in both parties being uncooperative and unwilling to clarify the incident with the police, because recording of an offence and investigation may result in charges for both parties. On the other hand, if the situation has escalated so that partners do not wish to stay in a relationship, both might be willing to start a criminal investigation against each other. Since the police are less likely to charge the assailant when they believe the victim is responsible for initiating the violence (Stewart \& Maddren, 1997), mutuality of violence may also cause police to not record an offence.

Presence of children. Concern about the possible consequences of child welfare intervention has been found to inhibit victims of DV from reporting DV incidents to police (Felson, 2002). On the other hand, it has been found that having children in the family and children witnessing $D V$ increases the probability of police knowing about the incident (MacQueen \& Norris, 2014; Akers \& Kaukinen, 2008). This is suggested to be explained by the victims' desires to protect children (MacQueen \& Norris, 2014). Children witnessing DV is also proposed as a motivation for victimized women to seek legal interventions to help end violent relationships (Akers \& Kaukinen, 2008). In Finland the police have a legal obligation to file a child welfare notification, and the involvement of children and the power of criminal investigation in protecting children might be an incentive for the police to record an offence.

Intoxication. Problematic alcohol use has been found to strongly associate with DV (e.g. Sprunger et al. 2015). Contradictorily, the police have been found to be more willing to investigate and help a victim who is cooperative, sober and rational, and is not resisting or yelling at the police (Robinson \& Chandek, 2000). Stewart and Maddren (1997) examined alcohol and gender in relation to victim blame that police assigned to parties of DV. Police officers were found to attribute more blame to drunken victims compared to sober victims in terms that drunken victims are seen as responsible for their own victimization, "by either provoking the violence or not evading the violence" (Stewart \& Maddren, 1997, p. 931). In addition, police officers blamed drunk assailants more when their victims were sober, compared to a sober assailants when their victim was drunk. In cases where the victim was drunk and the assailant was sober the blame was attributed equally on both. Victim blaming was connected to the police estimates about the likelihood of charging the assailant: charging the assailants was indicated to be less likely when the police blamed the victim (Stewart \& Maddren, 1997). Thus, it can be hypothesized in our study as well that recording of an offence is more likely when the victim is sober and the assailant is intoxicated. 
Repetitiveness of violence. Prior research indicates that being victimized by DV is among the strongest predictors for perpetrating DV. This finding applies to men as well as women (Finkel et al., 2009). DV can be described as a process in which mutual violence repeats and arouses aggression and is often accompanied by heavy abuse of intoxicants (Sprunger et al., 2015; Ruback et al., 2014). Repetitiveness of violence and visiting the same addresses repeatedly is a well-known situation for first-response police officers, and is also professionally frustrating. Robinson and Chandek (2000) conclude this based on officer tenure, which they found to affect officer assessment of victim cooperativeness and therefore also arrest decisions, so that more experienced officers developed a cynicism and viewed the victims more negatively over time (Robinson \& Chandek, 2000). Past incidents of DV have also been used as a variable in association with arrests, and the findings are mixed. Trujillo and Ross (2008) summarize that a history of DV does not seem to be associated or is even inversely associated with arrest. Hypotheses could be made in both directions: police officers seeing a repeated pattern as a warning of a possibly escalating situation and opting for a more serious response on one hand, and getting accustomed and becoming desensitized to incidents between certain people on the other.

Police workload pressure. Practical situational factors have gained very little attention in research concerning police response to DV. Police workload pressure can be identified as this type of practicality limiting the time that the police have to deal with one DV call out and the paperwork related to it. Robinson and Chandek (2000) claim previous studies including time of shift variables have failed to find a significant association because of failures in operationalization of the time constraint factor. They examined whether or not the DV incident occurred during the last hour of a police officer's shift, when presumably a time constraint exists, and found that the time of shift significantly decreased the probability of an arrest (Robinson \& Chandek, 2000). To our knowledge there are no prior studies examining officers' self-reported workload pressures as time constraint factors. However, as the time of shift variable would be sensitive to endings of shifts being different depending on, for example, day and time and other characteristics of the shifts, police officers' subjective estimations may offer one valid measure for a time constraint factor decreasing the probability of recording an offence.

\section{The current study}

In this study we examine which legal and extra-legal factors increase the probability of recording an offence on a police DV call out. Considering the jurisdiction that obligates the police to record every DV assault, including petty assaults even if the victim does not want an offence to be 
recorded, it is also important to look at the reasons the police give for not recording some of those incidents. Thus, the second part of our analysis is a categorization of police officers' free-text comments in response to the survey question about why an offence was not recorded. Based on the first two parts of the analysis we further look into reasons for not recording an offence on call outs in which the police have found it very likely or almost certain that violence had occurred, yet a decision was still made to not record the offence. The aim is to present the first results on police decision-making and discretion on DV call outs in the Finnish context of mandatory recording of offences.

\section{Data and method}

The analysis is based on data from the Police and Emergency Call database combined with survey responses by frontline police officers in one major police department in Finland. The starting point of the data collection was all the emergency calls in the Central Finnish Police Department area, labelled as DV by the Emergency Response Centre (hereafter ERC) during a six-month period from April to September 2015. The definition of a DV call out in the instructions for ERC operators is physical violence or noise referring to violence in an apartment, in which the parties are not necessarily family members (National Police Board 2014). For the purposes of police tactics and preparation for call outs there are separate definitions for incidents involving weapons as well as for homicide and sexual assaults in the police and ERC system, which means that some of the most serious call outs that could be recognized as DV are not labelled as such in the ERC. The data collected for this study was searched for from the system using the DV label of call outs, which means leaving most of the serious homicide-, sexual assault- and weapon-involving call outs that have separate call out categorizations outside the scope of our data. It should be noted that the most serious acts of violence are not the problematic cases concerning recording offence and also not in the focus of the 2011 legal reform, which changed the right to bring charges for petty assaults. Unclarities in official recording is not an issue in aggravated assaults and homicide, because these incidents are always recorded without any discretion. The call information for the ERC is seldom sufficient as itself, and in reality the data includes incidents ranging from pushing and shoving to threatening with a gun or using a knife. None of the incidents in our data turned out to be homicide.

The total number of calls labelled as DV during the six-month data collection period was 1,811 of which 1,627 were assigned to the police as call outs. The rest of these calls were either assessed as not needing police intervention in the first place or they were cancelled. In some cases the duty officers attended to the situation without visiting the scene and instead contacted the informant via 
phone. The police officers were asked to fill in a questionnaire about each call out they attended; one officer from each patrol on each call out. If the information about the police patrol in the emergency call database was incomplete, the email and the questionnaire were not sent. In addition, if the call out had been attended to without going to the scene, that is, via a phone call, the patrol did not receive the email regarding the questionnaire. This resulted in 1,431 sent emails regarding the DV call outs. A total of 1,047 responses to the questionnaire were received. The email was sent the next weekday following the call out, and it took about eight days on average for the police officers to answer. This was an expected time lag, since after working several weekend night shifts (during which DV call outs typically occur), the police have a few days off before the next workday.

The information from the ERC database and survey responses were merged using the specific time and date of the call out. Times and dates were collected from the ERC database and given to the police officers in the email in which they received the request to answer the survey concerning the particular call out. In 21 cases the time and date information given by the respondents was not specific, and these survey responses could not be merged with information from the ERC database. In addition, of 53 call outs two instead of one requested survey responses were received. The beginning of the survey included the following question: "How was evidence on violence gathered?" and in case the police chose "It was not gathered because no violence had occurred" the survey skipped other questions. This was done to take in to account false alarms and other call outs concerning which it was not meaningful to ask all the questions about victims and suspects and other conditions. When the double answers included one response indicating that evidence was not gathered because no violence had occurred, and another one which indicated that they questioned the people on the scene or did other investigatory actions, the latter was included in the merged data to gain more information about the circumstances which led the police to conclude that no violence had occurred. Concerning other double-answers, the response given after a shorter time after the call out was chosen with the presumption that the answer was produced by fresher memories.

After deleting 21 incomplete questionnaire responses and 53 double-answered call outs that could not be merged with the ERC data, the final data consisted of 973 cases that included both the data from the Police and ERC database as well as data from the questionnaire regarding the same call outs. This merged data represents 68 percent of the eligible pursued DV cases. However, despite the initial labelling of the emergency calls as DV, some of the cases proved to be something else in terms of the relationship between parties and actions that took place. This is natural, as the ERC officers have to label the calls based on whatever information they are able attain during an 
emergency call, whereas the police at the scene have more information based on their own observations.

The questionnaire included a question about the relationship between the suspected victim and perpetrator with the following alternatives: partner (including spouse, co-habiting partner or a partner); ex-partner (including ex-spouse, etc.); daughter/son; parent; other family member or a relative; acquaintance; unknown to each other; don't know. Based on the definition in the Finnish Criminal Code (Ministry of Justice, 2012), if the relationship was not recognized as a close relationship, i.e., acquaintance, unknown to each other or the police did not know about the relationship, the cases were excluded from the analysis in this paper. In addition, as the Finnish Criminal Code concerning assaults is not unambiguous about types of violence other than physical violence, although not restricted to physical harm, the question about what kind of violence the victim had experienced was used to exclude cases that involved mere threats. This is also because illegal threats are defined as complainant offences in the Finnish Criminal Code, and are therefore not in the scope of mandatory recording of offences. The final DV data $(\mathrm{N}=410)$ analysed in this paper thus consists of cases in which people involved were in a close relationship and the victim experienced some sort of physical violence. This outlining is also supported by the fact that physical violence is rather a universal criteria accepted in research concerning DV (Barrett et al., 2011; Hamberger \& Larsen, 2015, p. 701), which makes the analysis and results of this paper more easily applicable to other international contexts.

Assessment of the representativeness of our data has several challenges. The starting point of the data collection was all the DV call outs of one police department during a six-month data collection period and not, for example, a random sample. Our method of combining data from the ERC database with police survey data, and even surveying the police about DV call outs, is thus far unique in Finland, and therefore possibilities to assess the representativeness of our survey data are limited. Information obtained from victimization surveys would offer some comparable variables but would not be applicable, since our data only includes incidents that have come to the attention of the authorities. Furthermore, the official data on recorded DV offences is naturally limited to recorded incidents and does not include information in a form that could be compared to variables of our survey data. By comparing the whole data set $(\mathrm{N}=1811)$ to the survey sub data $(\mathrm{N}=973)$ we can conclude that some differences exist concerning variables that can be obtained in both data sets.

The police answered the survey concerning the most urgent call outs (A-class) slightly more often compared to the percentage of those call outs in the whole data set (27\% compared to $23 \%$ ). Call 
outs that were assigned in cities are overrepresented in the survey data (71\% compared to 65\%) compared to call outs in towns (20\% and $22 \%)$ and rural areas (9\% and $12 \%)$. The police answered the survey concerning call outs to repeated addresses slightly less often compared to the percentage of repeated addresses in the whole data set (24\% and 26\%). Call outs resulting in recording of offences are overrepresented in the survey data, which means that the police officers more often answered the survey when there was a reason to suspect violence and evidence to support it (35\% compared to 27\%). Limitations of conclusions resulting from this overrepresentation are discussed at the end of this paper.

Associations between recording an offence and explanatory factors are analysed using logistic regression analysis done as an enter model. In addition, cross-tabulation is used. Variables in the analysis have been chosen based on existing literature to examine whether the same factors found influential in the literature from other jurisdictions and policing yield results in the Finnish context. In addition to analysing the associations between recording an offence, and legal and extra-legal factors, reasons for not recording a crime based on police officers' free-text comments are categorized and listed according to their frequency in the data.

\section{Measures}

The dependent variable in the analysis is whether or not an offence was recorded based on the survey question to the police officers: "Was an offence recorded?" ( $0=$ no, $1=$ yes). The analysis of police officers' free-text comments is limited to incidents in which an offence was not recorded and based on the survey question: "Why wasn't an offence recorded?" In addition, twelve explanatory variables were included in the analysis.

Legal factors. Severity of violence $(0=$ mild physical violence, $1=$ severe physical violence $)$ was created as a dichotomous variable based on the question "If based on preliminary investigation there was a reason to suspect domestic violence had occurred, what of the following had the victim experienced?" with multiple choices of yelling, threatening behaviour (incl. throwing objects); threats of physical harm; restraining movement or grabbing; pushing or shoving; slapping; pulling hair; hit with a fist; hit with a hard object; kicked or strangled; used a weapon (incl. threatening with a weapon); attempt to force into sexual intercourse or other sexual interaction; forced into sexual intercourse or other sexual interaction; used other type of physical violence. Sexual violence was excluded from the analysis because of the unique characteristics and dynamics of the phenomenon and due to the small number of these incidents in the data, which in turn is the result of call outs related to sexual assaults being included in a different police operation code separate from DV. 
Mere threats were excluded from the data set, as illegal threats in the Finnish Criminal Code are complainant offences and not in the scope of our study. Restraining the victim from moving or grabbing him/her, pushing or shoving, slapping and pulling hair were categorized as mild physical violence that does not necessarily result in physical injuries. Hitting with a fist or with a hard object, kicking or strangling and the use of weapons were categorized as serious physical violence.

The likelihood of violence was inquired with the following question: "How likely did you think that violence had occurred?". There were only 12 responses in the first group of answers indicating that violence was not at all likely, and therefore the original four categories were recoded into three $(1=$ not at all likely or more or less likely, 2 = fairly likely, 3 = very likely or almost certain).

Extra-legal factors. In the survey the police ticked "gender of the victim" choosing between a woman/girl and a man/boy, and for the purposes of our analysis this was recoded to the victim being female $(0=$ no, $1=$ yes $)$.

The informant of the call was derived and coded based on call information in the ERC database $(0=$ other/unknown, 1 = neighbour, 2 = victim). The first category ("other/unknown") includes the informant being, for example, a friend of the victim calling from another address.

The following question was used to inquire about victim consent: "Did the patrol inquire about the willingness of the possible victim to report an offence?" ( $0=$ not inquired, $1=$ inquired $)$.

To find out if there was only one primary victim or whether violence was mutual, the aforementioned questions about the severity of violence were also asked concerning the primary assailant. If the assailants themselves had not experienced any form of physical violence it was interpreted as a call out involving one primary victim $(0=$ one victim, $1=$ mutual $)$.

Information about repetitive addresses was collected from the ERC data which includes the addresses to which call outs were assigned. A new variable was created based on multiple hits of the same address after which the original address information was deleted for anonymization. Repetitiveness of the address was coded as dichotomous $(0=$ no, $1=$ yes $)$.

To determine the involvement of children the following survey question was asked: "How many people were in the apartment when the police entered the scene?" with separate fields to enter the number of adults and the number or under-aged (younger than 18) people, and the number of children was recoded into whether or not any children were present $(0=$ no, $1=$ yes $)$. 
Victim sobriety was derived from the survey question "Did it appear in the situation that the victim was intoxicated?" with answering alternatives yes, no, I don't know. The variable of victim sobriety was recoded dichotomously ( $0=$ no, $1=$ yes) and not knowing was recoded as missing information. The same question was asked in the survey concerning the assailant, but the direction of the variable was recoded inversely as assailant being intoxicated $(0=$ no, $1=$ yes $)$.

Police workload pressure on a shift was inquired at the end of the survey as follows: "Estimate the workload pressure of the whole shift compared to a normal shift. Take into account how busy you were at the time, the amount of call outs and other strains." Original alternatives were "very heavy", "heavy", "normal", "relatively light" and "light". In order to create larger categories these were recoded into three new categories $(1=$ low, $2=$ average, $3=$ high $)$.

\section{Results}

\section{Incident characteristics}

The descriptive statistics of the data is presented in Table 1 . Of the $410 \mathrm{DV}$ call outs that were identified as including at least some type of physical violence and occurring in a close relationship, an offence was recorded in 68 percent of the cases. Type of violence was mild in 52 and severe in 46 percent of the call outs. In five percent of the call outs the victim experienced other types of physical violence that could not be directly categorized as mild or severe. Only in 12 cases percent the police estimated it was not at all likely that violence actually happened, and therefore the first category of answers were merged with "more or less likely" category, resulting in 35 percent of the call outs. In 26 percent of the call outs violence was estimated to be fairly likely, and in 39 percent of the call outs it was seen as very likely or almost certain. The primary victim was female in 80 percent of the call outs, and the victim called the ERC in 57 percent of the cases. The victim's consent to record an offence was inquired in almost three out of four of the call outs, but the information about the inquiry was missing in as many as 16 percent of the cases. Mutual violence occurred in one third of the call outs. In 26 percent of the call outs police visited the same address at least twice during the six-month data collection period. Children under 18 were present at the scene of the call out in 17 percent of the incidents. Intoxication was a dominant feature: in 57 percent of the call outs the victim was intoxicated and in 66 percent of the call outs the assailant was intoxicated. Police workload pressure was estimated as being light in 10 percent of the call outs, normal in 70 percent (the most common statistic) and high in 20 percent of the call outs. 
Table 1 Descriptive statistics of the data $(\mathrm{N}=410)$

Variable and Value

n $\%$

Offence recorded

$0=$ No

$130 \quad 32$

$1=$ Yes

$280 \quad 68$

Seriousness of the violence

$0=$ Mild physical violence

$212 \quad 52$

$1=$ Severe physical violence

17846

Missing

205

Likelihood of violence

$1=$ Not at all likely or more or less likely

$145 \quad 35$

$2=$ Fairly likely

10626

$3=$ Very likely or almost certain

$159 \quad 39$

Victim female

$0=$ No

$83 \quad 20$

$1=$ Yes

$327 \quad 80$

Informant position

$1=$ Unknown/other

$140 \quad 34$

$2=$ Neighbor

369

$3=$ Victim

Victim consent for recording an offence inquired

$0=$ Not inquired

$46 \quad 11$

$1=$ Inquired

29973

Missing

$65 \quad 16$

Mutuality of violence

$0=$ One victim

$273 \quad 67$

$1=$ Mutual violence

$137 \quad 33$

Repeated address

$0=\mathrm{No}$

$303 \quad 74$

$1=$ Yes

$107 \quad 26$

Children present

$0=$ No

$339 \quad 83$

$1=$ Yes

Victim sober

$0=\mathrm{No}$

$232 \quad 57$

$1=$ Yes

15638

Missing

$22 \quad 5$

Assailant intoxicated

$0=\mathrm{No}$

$\begin{array}{ll}110 & 27\end{array}$

$1=$ Yes

$272 \quad 66$

Missing

287

Workload pressure on shift

$1=$ Light

$41 \quad 10$

$2=$ Normal

28670 


\section{Factors increasing the probability of recording an offence}

The logistic regression model is presented in Table 2. Severity of violence increases the probability of recording the offence the most (OR 11.65). A police officer's assessment of the likelihood of violence adds to the risk of recording an offence, and the risk increases in both "fairly likely" (OR 11.56) and "very likely or almost certain" category (OR 22.99) compared to the reference category ("not at all likely or more or less likely"). Third most considerable is the effect of gender on the probability of recording an offence: the victim being a female explains the probability of recording the offence significantly (OR 6.36). The informant being a neighbour does not increase the probability of recording compared to the reference group ("unknown or other"), but the informant being the victim adds to the risk of recording (OR 2.39). Other factors in the model are not statistically significant.

\section{Reasons not to record $D V$ as an offence}

Table 3 presents the descriptive statistics for different explanations in police officers' free-text comments regarding the question of why an offence was not recorded. Explanations mentioned more than five times in the data are included in the categorization. The total number of explanations exceeds the number of comments, since one comment may include several different reasons why an offence was not recorded. The percentage of each explanation is counted from the number or comments.

The most common explanation given for not recording an offence was that the victim did not want or did not insist that the incident would be recorded. This group of explanations also includes comments stating that the incident was a complainant offence or that the victim will later report the incident as an offence if he or she feels like it. The second most common explanation was that there were no injuries, which was mentioned in one third of all free-text comments. Almost as common was the explanation that the incident was only a petty assault. 
Table 2 Logistic regression predicting recording an offence on a DV call out

\begin{tabular}{|c|c|c|c|c|}
\hline & \multirow[t]{2}{*}{ Wald } & \multirow[t]{2}{*}{$\operatorname{Exp}(B)$} & \multicolumn{2}{|c|}{$\begin{array}{c}\text { 95\% C.I.for } \\
\operatorname{EXP(B)}\end{array}$} \\
\hline & & & Lower & Upper \\
\hline \multicolumn{5}{|l|}{ Severity of violence } \\
\hline severe & 32.226 & $11.646^{* * *}$ & 4.990 & 27.182 \\
\hline \multicolumn{5}{|l|}{ Likelihood of violence } \\
\hline fairly likely & 28.918 & $11.562 * * *$ & 4.738 & 28.213 \\
\hline very likely or almost certain & 41.557 & $22.987 * * *$ & 8.862 & 59.625 \\
\hline \multicolumn{5}{|l|}{ Female victim } \\
\hline yes & 12.762 & $6.355 * * *$ & 2.304 & 17.527 \\
\hline \multicolumn{5}{|l|}{ Informant } \\
\hline neighbour & .333 & .692 & .198 & 2.417 \\
\hline victim & 4.560 & $2.394^{*}$ & 1.074 & 5.333 \\
\hline \multicolumn{5}{|l|}{ Victim consent inquired } \\
\hline inquired & .044 & 1.127 & .368 & 3.448 \\
\hline \multicolumn{5}{|l|}{ Mutuality of violence } \\
\hline mutual violence & .047 & .916 & .415 & 2.025 \\
\hline \multicolumn{5}{|l|}{ Repeated address } \\
\hline yes & .687 & .700 & .301 & 1.628 \\
\hline \multicolumn{5}{|l|}{ Children present } \\
\hline yes & .018 & .932 & .332 & 2.620 \\
\hline \multicolumn{5}{|l|}{ Victim sober } \\
\hline yes & 2.339 & 2.028 & .820 & 5.018 \\
\hline \multicolumn{5}{|l|}{ Assailant intoxicated } \\
\hline yes & .850 & 1.549 & 611 & 3.925 \\
\hline \multicolumn{5}{|l|}{ Workload pressure on shift } \\
\hline normal & 1.681 & .532 & .205 & 1.381 \\
\hline heavy & 3.089 & .273 & .064 & 1.161 \\
\hline $\mathrm{N}$ & 320 & & & \\
\hline Nagelkerke R Square & .603 & & & \\
\hline Hoshmer and Lemeshow Test & $3,260(8) p>.05$ & & & \\
\hline
\end{tabular}

Note. $* \mathrm{p}<.05 . * * \mathrm{p}<.01 . * * * \mathrm{p}<.001$. Reference categories: mild violence, violence not at all likely or more or less likely, male victim, informant unknown or other, victim consent not inquired, only one victim, not a repeated address, no children present, victim not sober, assailant not intoxicated, low workload pressure for the police.

Other explanations were mentioned in less than 20 comments. "Lack of any evidence" is almost, yet not quite a synonym for the group of explanations referred to by the description "no injuries". In a way the difference between the frequencies of these two explanations highlight the meaning of physical harm in police understanding of DV. "No physical violence/assault" and "Not a crime/no reason to suspect" as explanations are controversial, as the cases analysed here are all call outs in 
which the police suspected at least some level of physical violence had occurred according to the question of what type of violence had been experienced by the victim. Stating that people had other reasons to call the police than recording an offense or that another response was seen as appropriate, both reasons mentioned in 12 percent of the comments, seem to suggest police discretion and disagreement with the current legislation. Altogether, in 19 comments the incidents and people on the call outs were described as too disorderly for the police to have any basis to record an offence. Mutual violence as an explanation for not recording an offence was mentioned in seven call outs.

Table 3 Frequency of explanations to why an offence was not recorded

\begin{tabular}{lcc} 
& fq & \% \\
\hline Victim didn't want or didn't insist/complainant offence & 78 & 60 \\
No injuries & 42 & 32 \\
Only a petty assault & 37 & 28 \\
No evidence & 19 & 15 \\
No physical violence/assault & 16 & 12 \\
Other response was appropriate & 15 & 12 \\
People had other reason to call the police & 15 & 12 \\
Not a crime/no reason to suspect & 12 & 9 \\
Incident could not be clarified & 12 & 9 \\
Incident could not be clarified due to alcohol/drug abuse & 7 & 5 \\
Violence was mutual & 7 & 5 \\
\hline
\end{tabular}

$\mathrm{N}$ of comments $=130$

\section{Recording an offence according to the likelihood of violence}

For the third and final part of the analysis we cross-tabulated recording an offence with the police assessment on the likelihood of violence. Even though all the incidents included in the analysis are those in which the police assessed that some sort of physical violence had occurred, the free-text comments reveal that injuries and other evidence were not always found, meaning that the police had to assess the likelihood of violence based on the original emergency call and on the description by the suspected victim and assailant. Incidents in which the police assessed violence as being very likely or almost certain, yet they still refrained from recording an offence, are at the core of analysing police discretion and the implementation of mandatory recording of DV offences. This is because these likely cases of violence are not prone to lack of evidence. The variable of severity of violence can be prone to the lack of evidence if assessment of severity is based solely on victims' claims (i.e., the victim says he/she was strangled but there are no visible injuries). The call outs where the likelihood of violence is regarded as being high should represent the least uncertainty for the police regarding whether or not to record an offence. 
The cross-tabulation in Table 4 shows that an offence was not recorded on 16 (10\%) DV call outs in which the police assessed the likelihood of violence as being very likely or almost certain. Free-text comments concerning these 16 incidents highlight the same explanations that were given for all DV call outs in which an offence was not recorded: the victim did not want or did not insist that an offence should be recorded. This most common reason was mentioned in 12 out of 16 call outs.

The incident was a petty assault and the victim insisted the offense not be recorded. She called the police mainly because she wanted her partner to understand that this behaviour is not acceptable.

Petty assault or mild physical violence was mentioned in seven of these 16 call outs and "no injuries" were mentioned in four cases. Some of the comments include clear signs of misconceptions concerning the obligation to record even petty assaults when occurring in a close relationship:

The husband explained he would consider filing a report until Monday. The wife had no desire to have a report filed.

It was a petty assault, which is a complainant offence. The victim will file a report later if they see it as necessary.

Of note is also that (mental) health problems were brought up by the police in two of these call outs in which the police assessed that the violence was very likely or almost certain, but did not record an offence.

The complainant had no injuries. The wife did not want to record an offence against her husband. She only wanted him to get medical help. Violence was the result of the man's illness and he did not understand his own actions. The couple has been together for 68 years; the wife is his caregiver.

Table 4 Recording an offence according to the likelihood of violence assessed by the police, $\%$ (n).

\section{Offence recorded}

\begin{tabular}{lccc} 
Likelihood of violence & No & Yes & $\mathrm{n}$ \\
\hline Not at all likely & $92(11)$ & $8(1)$ & 12 \\
More or less likely & $63(84)$ & $37(49)$ & 133 \\
Fairly likely & $18(19)$ & $82(87)$ & 106 \\
Very likely or almost & $10(16)$ & $90(143)$ & 159 \\
certain & & & 410
\end{tabular}




\section{Discussion}

This study provides the first empirical results on the implementation of a mandatory recording policy regarding DV call outs in Finland. The evidence, based on official Police and ERC data merged with survey responses by police officers, shows that despite the mandatory recording policy consolidated in the 2011 reform in the Finnish Criminal Code, police discretion in recording remains: not all incidents, which according to the police occur in close relationships and include the use of physical violence, are recorded as offences. In addition to legal factors, which in our analysis included severity of violence and police assessment of the likelihood of violence, some extra-legal factors affect the probability of recording an offence on a DV call out. These are gender of the victim and the position of the informant.

The results indicating that, examined from the police perspective, the severity and likelihood of violence increases the risk of recording DV as an offence, are not particularly surprising. The more serious the violence, the more probable it is that there are also visible injuries and other evidence supporting the probability. There is also less doubt concerning the police discretion of whether or not the claimed act constitutes a criminal offence, if the assessment concerning recording the offence differentiates between aggravated assault or assault compared to petty assault or no assault at all.

The relevance of the informant's position in relation to the recording of an offence can be explained by the fact that unknown and other informants in the data were often people who were not at the scene of the action when the assumed violence happened, and thus an emergency call from them was more likely to be a false alarm compared to a call by a neighbour listening to the altercation, let alone the victim themselves. The victim may also be more willing to cooperate with the police to contribute to the criminal investigation if he or she was the one who contacted the police in the first place. The lack of willingness or demands by the victim are still in many cases considered by the police when deciding whether or not to record DV as an offence, and proof of this was revealed in police officers' free-text comments. Petty assaults in close relationships were often perceived as still being complainant offences and this was the most common reason for not recording an offence.

The finding that the risk of recording increased if the victim was female merits further discussion, especially because severity of violence does not seem to override the gender effect. Prior studies have shown that, concerning crimes in general, victims are more likely to contact the police when they are victimized by men (Wong \& Schoot, 2012), and the majority of DV call outs in our Finnish data also included a female victim and male assailant. Our results show that the gender effect is 
repeated in recording of offences: the police are more likely to record DV as an offence when the primary victim is a woman compared to the victim being a man, and this was true even concerning severe physical violence ${ }^{\mathrm{ii}}$. This is contrary to some previous findings that have mentioned gender as one of the less influential factors initiating police action (Horwitz et al. 2011, p. 619), yet supported by Brown's study which recognized that the entire criminal justice system treats male to female violence more severely than female to male violence (Brown, 2004). Men are particularly unlikely to report an assault by their female partners (Felson \& Paré, 2005) and when they do, they often face serious barriers in help-seeking in the systems that are mainly focused on helping women (Douglas \& Hines, 2011). Douglas and Hines (2011) conclude that the concept of a female assailant does not fit the theoretical perspective of patriarchal constructions that is currently dominant in research concerning causes of intimate partner violence.

As mentioned above, the most common reason given for not recording an offence based on police free-text comments was that the incident was perceived as a complainant offence and thus the responsibility of filing it was left to the victim. Since the data only included incidents in which a police officer had responded that the parties were in a close relationship and that at least some sort of physical violence occurred, none of the cases would in theory be complainant offences. This indicates that the current legislation concerning the right to bring charges for assaults occurring in close relationships is not clear to all police officers. Despite responding that some sort of physical violence occurred, the likelihood of violence varied, most likely due to the amount of available evidence. Still, unawareness of the current legislation seems to concern both the definition of a close relationship and also petty assaults in a close relationship not being complainant offences.

\section{Policy implications}

When the police have arrived at a DV call out scene, in cases where physical evidence for DV is unclear and especially when the victim does not specifically report actions considered as offences, the implementation of mandatory recording of offences seems unclear. Even when claims of physical violence have been stated by the victim, based on free-text comments by the police, the victim's willingness and perhaps even demands are crucial when the police assess whether or not an offence should be recorded and pre-trial investigation started. Viewed against the 2011 reform in the Finnish Criminal Code this seems problematic, as the purpose of the change was to take the burden away from the victim and assure that the issue would proceed to the criminal justice process without the case being closed due to, for example, the victim being afraid of the assailant (Finnish Government, 2010). This was at the core of the legal reform that took place in 2011 to efficiently 
tackle DV. In practice, however, the result can often be similar to that before the legal reform if the victim refuses to tell anything about the incident and other evidence concerning even a petty assault may be lacking.

The remaining police discretion based on victim preferences is not necessarily purely a negative finding, as much of the literature assessing pro- and mandatory arrest policies have recommended that the victim's perspective should not be overridden by the expected, yet contested, efficiency of coercive police responses to DV (e.g. Akers \& Kaukinen, 2008; Leisenring, 2012). Pro- and mandatory arrest policies and mandatory recording of offences are based on the similar idea of assuring a more intensive response to DV by decreasing the possibilities for both victim and police discretion. But it can be seen in both examples internationally (e.g. Horwitz et al., 2011; Grant \& Rowe 2011) and in our Finnish data that some level of discretion remains in practical police work and victim's preferences, as well as other extra-legal factors, continue to play a part in police first response decision making.

Gender of the victim as a significant factor affecting the probability of recording an offence can be seen as particularly problematic. The result that recording DV as an offence is more likely when the victim is female compared to male, even concerning serious violent incidents, suggests that more attention should be paid to ensure equal and sensitive police response to DV regardless of victim and assailant gender. Policy implications related to this finding are not unique (see for example Leisenring, 2012), but perhaps so far undervalued.

Of importance is also the finding that repetitiveness of visiting an address did not increase the probability of recording DV as an offence. Similar findings have been previously reported when examining factors increasing the probability of arrest (Robinson \& Chandek 2000). Results from an Australian study by Trujillo and Ross (2008) indicate that police officers find occurrence of previous DV incidents to be among the most important factors in their assessment of risk, and taking action such as filing charges. It is alarming that the risk of escalating violence in repeat addresses does not seem to be recognized in our data of DV call outs. Consequently, we see this as an indication of the need for risk assessment tools for the Finnish police. Focusing on the recording policy adopted in Finland, other police responses on these same call outs were not analysed in this paper, which points to the need for further research.

More flexibility in police response based on uniqueness of each DV call out has been suggested in relation to pro- and mandatory arrest policies to better consider the victims' needs (Leisenring, 2012) and the pro- or mandatory recording policy of offences adopted in Finland could be criticized 
on similar grounds. In addition, Grant and Rowe (2011, p. 49) have concluded that in developing more efficient policing concerning DV "the reduction of officer discretion through policy and procedure seems unlikely to provide a viable solution". In our data the police officers' free-text comments concerning the need for health services instead of criminal procedures is one example of a situation in which the police can face an ethical dilemma between the mandatory recording policy and the needs of the parties of violence. Assessment should be done on both the policy and legislative level concerning whether the purposed policy of recording each DV incident as an offence is meaningful for the purposes of helping victims and preventing further violence.

The foremost important policy implication includes a suggestion of factors contributing to policy effectiveness. As research on policing DV and arrest policies have shown, police response to DV should not be examined in a vacuum (Bourg \& Stock, 1994; Horwitz et al. 2011). What happens after or in conjunction with arrest or recording an offence may be almost as influential as the first response itself. This is also supported by findings that reporting to the police (irrespective of signing a complaint) has a deterrent effect regardless of an arrest (Felson et al. 2005) which may be because reporting to the police might initiate other intervention outside the criminal justice system. Recognizing the role and influence of community work and social services on parties of DV as well as assuring the resources for these services could be the key element for more effective policies concerning police response to DV, regardless of whether the response is making an arrest or recording of an offence.

\section{Limitations}

Some limitations should be acknowledged concerning our study. The aim of the data collection was to include all the call outs of one police department and not, for example, to collect a random sample of call outs across the country. Although data collection succeeded at a generally good response rate of 68 percent, there is also missing information in the survey data, and the incidents that resulted in recording an offence are slightly overrepresented. Missing information at different stages of the data forming process add some uncertainty to the strength of our findings. Even though missing information precludes us from straightforwardly evaluating the magnitude of, for example, the misunderstanding concerning the current legislation among the police, the finding that it is an existing phenomenon is an important one. It should be, however, noted that there might also be other reasons for not recording an offence on a DV call out than those found in this study. Taking into consideration the sensitive nature of the possible resistance to current legislation by the 
law enforcement community themselves, unawareness of the mandatory recording of offences may also include unwillingness that was not directly phrased in free-text comments by the police. Concerning a survey for the police with the topic of a DV call out, this might be one plausible reason for non-response and the missing data.

The definition of DV in our study has potential for some skewness of the data. On one hand, as the starting point of our data collection were the police DV call outs, our data is thoroughly affected by the official definition of a police DV call out, which focuses on physical violence. On the other hand, police call outs involving weapons or homicide, for example, have a label overriding the DV label of a call out, which means that some extreme cases of DV would not be part of our data. The ERC operators do not always receive sufficient or correct information in an emergency call, thus, incidents labelled as DV may include weapons as well as homicide, and incidents with a weapon call out label may turn out to be other type of violence and DV. None of the incidents in our data turned out to be homicide, thus, our data does not include DV homicide. It should be noted, however, that the most serious incidents of DV (incl. homicide) are not an issue in whether a written recording of DV is made by the police, because these incidents are always recorded and investigated. Since the focus of our study was to examine the factors increasing the risk of recording a DV offence, the DV call out label as a starting point to our data collection does not result in substantial skewness in our data.

Since only one police department in Finland was included in this study we cannot generalize the results to other police departments. Given that the Criminal Code is the same for every police department in Finland we can, however, reasonably assume that there should not be differences between police departments in how the recording of offences and the investigation of DV cases are interpreted across the country. In case some police departments have, for example, a working culture with more awareness concerning gender issues and equality, the result concerning gender effect on recording offences may not be applicable elsewhere.

Our analysis is limited to factors that were available in our combined data of the ERC database and police survey responses. Studies concerning pro-arrest policies have also found other factors than those examined here to explain arrest decisions, but not all of them could be tested here in association with recording of offences. The unit of observation in this study was a DV call out, and thus the variables included in the analysis are focused on situational factors and not so much on victim or assailant characteristics. The focus of our study and therefore also the data was such that it does not make it possible to analyse victim characteristics in detail. The possibility of analysing 
more victim-related factors could have produced different kinds of results compared to our situational-focused research design. Future research should address this problem by replicating this method of data collection in other police departments, and for further comparisons also in other jurisdictions. 


\section{References}

Aaltonen, M., Salmi, V., \& Kivivuori, J. (2014). Examining offender characteristics in policerecorded domestic violence before and after a legal reform. International Criminal Justice Review, 24(3), 271-284. doi: 10.1177/1057567714548454

Akers, C. \& Kaukinen, C. (2009). The police reporting behavior of intimate partner violence victims. Journal of Family Violence, 24(3), 159-171. doi: 10.1007/s10896-008-9213-4

Arnocky, S., \& Vaillancourt, T. (2014). Sex differences in response to victimization by an intimate partner: More stigmatization and less help-seeking among males. Journal of Aggression, Maltreatment \& Trauma, 23, 705-724. doi: 10.1080/10926771.2014.933465

Barrett, B. J., St. Pierre, M., \& Vaillancourt, N. (2011). Police response to intimate partner violence in Canada: Do victim characteristics matter? Women \& Criminal Justice, 21, 38-62. doi: $10.1080 / 08974454.2011 .536057$

Bourg, S., \& Stock, H. V. (1994). A review of domestic violence arrest statistics in a police department using a pro-arrest policy: Are pro-arrest policies enough? Journal of Family Violence, 9(2), 177-189.

Brown, G. A. (2004). Gender as a factor in the response of the law-enforcement system to violence against partners. Sexuality and Culture, 8, 3-139.

Council of Europe (2011). Convention on Preventing and Combating Violence against Women and Domestic Violence. Council of Europe Treaty Series - No. 210. www.coe.int/conventionviolence.

Danielson, P. \& Kuitunen, L. (2017). Suomalaisten kokema parisuhdeväkivalta 2015 - Kansallisen rikosuhritutkimuksen tuloksia. [Intimate partner violence experienced by Finnish people 2015. Results of the National Crime Victim Survey]. University of Helsinki, Institute of criminology and crime prevention. (forthcoming)

Douglas, E. M., \& Hines, D. A. (2011). The helpseeking experiences of men who sustain intimate partner violence: An overlooked population and implications for practice. Journal of Family Violence, 26(6), 473-485. doi: 10.1007/s10896-011-9382-4

Felson, R. B., Ackerman, J. M., \& Gallagher, C. A. (2005). Police intervention and the repeat of domestic assault. Criminology 43(3), 563-588. 
Felson, R. B., Messner, S. F., Hoskin, A. W., \& Deane, G. (2002). Reasons for reporting and not reporting domestic violence to the police. Criminology, 40, 617-648.

Felson, R.B., \& Paré, P.P. (2005). The reporting of domestic violence and sexual assault by nonstrangers to the police. Journal of Marriage and Family, 67, 597-610.

Finnish Government. (2010). Government Bill 78/2010 vp. Helsinki: Council of State.

Finkel, E. J., DeWall, C. N., Slotter, E. B., Oaten, M., \& Foshee, V. A. (2009). Self-regulatory failure and intimate partner violence perpetration. Journal of Personality and Social Psychology, $97,483$.

Frye, V., Haviland, M., \& Rajah, V. (2007). Dual arrest and other unintended consequences of mandatory arrest in New York City: A brief report. Journal of Family Violence, 22(6), 397-405. doi: 10.1007/s10896-007-9094-y

Hamberger, L. K., \& Larsen, S. E. (2015). Men's and women's experience of intimate partner violence: a review of ten years of comparative studies in clinical samples; part I. Journal of Family Violence, 30(6), 699-717. doi: 10.1007/s10896-015-9732-8

Holma, J. \& Partanen, T. (2008). Lähisuhdeväkivalta tutkimuskohteena. [Violence in close relationships as a research topic.] In: E. Sevón \& M. Notko (Eds.) Perhesuhteet puntarissa. [Family relationships weighted]. Helsinki: Palmenia, 274-291.

Horwitz, S. H., Mitchell, D., LaRussa-Trott, M., Santiago, L., Pearson, J., Skiff, D. M., \& Cerulli, C. (2011). An inside view of police officers' experience with domestic violence. Journal of Family Violence, 26(8), 617-625. doi: 10.1007/s10896-011-9396-y

Hoyle, C., \& Sanders, A. (2000). Police response to domestic violence. British Journal of Criminology, 40, 14-36.

Johnson, I. M. (2007). Victims' perceptions of police response to domestic violence incidents. Journal of Criminal Justice, 35, 498-510.

Jordan, J. (2002). Will any woman do? Police, gender and rape victims. Policing: An International Journal of Police Strategies \& Management, 25, 319-344. 
Kaukinen, C. (2004). The help-seeking strategies of female violent-crime victims the direct and conditional effects of race and the victim-offender relationship. Journal of Interpersonal Violence, 19, 967-990.

Lee, J., Zhang, Y., \& Hoover, L. T. (2013). Police response to domestic violence: multilevel factors of arrest decision. Policing: an International Journal of Police Strategies \& Management, 36, 157174. doi: $10.1108 / 13639511311302524$

Lehti, M. (2016). Henkirikoskatsaus 2016. [Homicide Review 2016]. Institute of Criminology and Legal Policy Reviews 10/2016. Helsinki: University of Helsinki.

Leisenring, A. (2012). Victims' perceptions of police response to intimate partner violence. Journal of Police Crisis Negotiations, 12, 146-164. doi: 10.1080/15332586.2012.728926

Ministry of Justice. (2012). The Criminal Code of Finland (unofficial translation). Helsinki: Ministry of Justice.

Ministry of Justice (2015). Criminal Investigation Act (unofficial translation). Helsinki: Ministry of Justice.

National Police Board (2014). Tehtävälajikohtaisia kiireellisyysarvioita ja ohjeita poliisin teht'vien käsittelyssä sekä toimenpidekoodit [Instructions for assignment urgency, processing of assignments and operational codes]. Appendix 2/2014 to the instruction of the National Police Board POL-201410336.

Newbold, G., \& Cross, C. (2008). Domestic violence and pro-arrest policy. Social Policy Journal of New Zealand, 33, 1-14.

Phillips, S. W. (2008). Mandatory arrest: loosely coupled organisations, situational variables, and the arrest decision. International Journal of Police Science \& Management, 10, 374-387.

Piispa, M., Heiskanen, M., Kääriäinen, J. \& Sirén, R. (2006). Naisiin kohdistunut väkivalta 2005 [Violence against women in 2005]. Helsinki, Finland: National Research Institute of Legal Policy/HEUNI.

Robinson, A. L., \& Chandek, M. S. (2000). The domestic violence arrest decision: Examining demographic, attitudinal, and situational variables. Crime \& Delinquency, 46, 18-37. 
Robinson, A. L. (2006). Reducing Repeat Victimization Among High-Risk Victims of Domestic Violence The Benefits of a Coordinated Community Response in Cardiff, Wales. Violence Against Women, 12, 761-788. doi: 10.1177/1077801206291477

Robinson, A. L., Pinchevsky, G. M., \& Guthrie, J. A. (2016). Under the radar: policing non-violent domestic abuse in the US and UK. International Journal of Comparative and Applied Criminal Justice, 1-14. doi: 10.1080/01924036.2015.1114001

Sherman, L. W., \& Berk, R. A. (1984). The Specific Deterrent Effects of Arrest for Domestic Assault. American Sociological Review, 49, 261-272.

Stewart, A., \& Maddren, K. (1997). Police officers' judgements of blame in family violence: The impact of gender and alcohol. Sex Roles, 37, 921-933. doi: 10.1007/BF02936347

Trujillo, M. P., \& Ross, S. (2008). Police response to domestic violence making decisions about risk and risk management. Journal of Interpersonal Violence, 23, 454-473. doi:

$10.1177 / 0886260507312943$

Wong, T. M., \& Van de Schoot, R. (2011). The effect of offenders' sex on reporting crimes to the police. Journal of Interpersonal Violence, 27, 1276-1292. doi: 10.1177/0886260511425245 


\section{Notes}

${ }^{\mathrm{i}}$ The definition of assault in the Finnish Criminal Code (Ministry of Justice, 2012) is the following: A person who employs physical violence on another or, without such violence, injures the health of another, causes pain to another or renders another unconscious or into a comparable condition, shall be sentenced for assault to a fine or to imprisonment for at most two years.

Assault is defined as aggravated assault

If in the assault

(1) grievous bodily injury or serious illness is caused to another or another

is placed in mortal danger, (2) the offence is committed in a particularly brutal or cruel manner, or

(3) a firearm, edged weapon or other comparable lethal instrument is used

and the offence is aggravated also when assessed as a whole, the offender shall

be sentenced for aggravated assault to imprisonment for at least one year and at most ten years.

Petty assault is defined as follows:

If the assault, when assessed as a whole and with due consideration to the minor significance of the violence, the violation of physical integrity, the damage to health or other circumstances connected to the offence, is of minor character, the offender shall be sentenced for petty assault to a fine.

The right to bring charges has since 2011 been defined as follows:

The public prosecutor may bring charges for petty assault only if the injured party reports the offence for the bringing of charges or the offence was directed at (1) a person below the age of eighteen years; (2) the offender's spouse or former spouse, sibling or direct ascending or descending relative or a person who lives or has lived in a joint household with the offender or otherwise is or has been in a corresponding personal relationship with the offender or is close to him or her; or (3) a person due to his or her employment and the offender is not part of the personnel at the place of employment.

The public prosecutor may bring charges for the negligent bodily injury only if the injured party reports the offence for the bringing of charges.

ii It should be taken into account that some of the most serious DV incidents are not included in the data because homicides, for example, have a separate call out label for the purpose of adequate police operational preparation. In so far as the ERC operator has had accurate and sufficient information to label the call out, this data on DV call outs should not include homicides and other extreme cases of DV, yet, in reality this data does include some call outs in which weapons were used. 